\title{
Prevalence of malaria among blood donors in blood bank, Jhalawar Hospital \& Medical College Society, Jhalawar, Rajasthan
}

\author{
Manish Kumar', Shakyawal B. ${ }^{2}$, Madan Y. ${ }^{3}$ \\ ${ }^{1}$ Dr. Manish Kumar, Assistant Professor, ${ }^{2}$ Dr. Brajendra Shakyawal, Assistant Professor, ${ }^{3}$ Dr. Yogendra Madan, \\ Assistant Professor, all authors are affiliated with Department of Pathology, Jhalawar Medical College, Jhalawar, \\ Rajasthan, India.
}

Corresponding Author: Dr. Brajendra Shakyawal, in front of Bijasanmatapark, Keshavpura, Sector-4, Kota, Rajasthan. E-mail: bshakyawal@gmail.com

\begin{abstract}
Introduction: Transfusion Transmitted Malaria (TTM) is the great concern in endemic countries. Transmission of malaria by blood transfusion was one of the first recorded incidents of transfusion transmitted infection. The drugs and cosmetic act in India mandates the testing of all blood donations for human immunodeficiency virus (HIV) hepatitis B surface antigen (HbsAg), hepatitis $\mathrm{C}$ virus (HCV), malaria and syphilis. The present study aims to determine the prevalence of malarial among voluntary and replacement blood donors in Blood Bank, Jhalawar Hospital \& Medical college society, Jhalawar, Rajasthan. Material and Methods: A retrospective review of donors record covering the period between Jan 2017 to Dec 2017 at Blood Bank, Jhalawar Hospital \& Medical college society, Jhalawar, Rajasthan, India. The blood samples were then obtained by standard procedures of venepuncture. Malarial parasites were screened by microscopy (peripheral blood smear) and rapid Antigen card detection in blood bank. The study detected the presence of malaria parasites in donated blood units. Results: 5 out of 16495 donor population were positive (Prevalence $0.03 \%$ ) on Immunochromatographic rapid diagnostic test for malarial antigen detection (Rapid Antigen Card Test). Conclusion: Blood donors in Blood Bank, Jhalawar Hospital \& Medical college society, Jhalawar, Rajasthan, India have a 0.03\% prevalence and voluntary donations are safer as compared to replacement donation. By strict donor selection, proper donor testing and post testing counselling, the rate of TTM can be further minimized.
\end{abstract}

Keywords: TTM, Blood Donors, Peripheral blood smear, Rapid Antigen Card Test, Malaria, Microscopy

\section{Introduction}

Blood donation is the most important and essential part of blood transfusion services, usually donated voluntarily or in the form of replacement. Millions of lives are saved each year through blood transfusions, who have lost large volumes of blood from serious accidents, major Surgical Operation, Cancer patients requiring therapy, women with haemorrhage at child birth, patients of hereditary disorders like Haemophilia and Thalassaemia, severe burn victims as well as for individuals who have symptomatic anemia from medical or hematologic conditions or cancers.

Blood transfusion carries the risk of transmitting major infections such as hepatitis, HIV, syphilis, and malaria. In minority cases, viral infections such as cytomegalovirus, herpes virus, and Epstein-Barr virus along with toxoplasmosis and brucellosis may be transmitted [1].

Manuscript received: $4^{\text {th }}$ February 2019

Reviewed: $14^{\text {th }}$ February 2019

Author Corrected: $20^{\text {th }}$ February 2019

Accepted for Publication: $26^{\text {th }}$ February 2019
Therefore Blood banks are obligated to provide adequate and safe blood to the community. In India, it is mandatory to test every unit of blood collected for hepatitis B, hepatitis C, HIV, syphilis and malaria [2]. The donated blood was discarded whenever the pilot donor sample was found positive for any TTI. Transmission of malaria by blood transfusion was one of the first recorded incidents of transfusion transmitted infection [3]. Testing of blood for malarial parasite is mandatory as per the drugs and cosmetic act part X11 B of Schedule F.

Although malaria transmission occurs principally through mosquito bites, transfusion-transmitted malaria (TTM) is an accidental Plasmodium infection caused by the transfusion of whole blood or a blood component from a malaria infected donor to a recipient, described for the first time by Woolsey in 1911. The frequency of transfusion transmitted malaria varies from 0.2 per million cases fornon-endemic countries to 50 or more 
cases per million in endemic areas [4]. The microscopic detection of blood though considered the gold standard for malaria diagnosis for decades, it is quite labor intensive and require adequate technical skill and man power. This had spurred the development of other microscopic malarial and rapid detection test based on the detection of malarial parasite antigen in the whole blood [5]. Donors who are implicated as the source of transfusion transmitted malaria cases typically have very low level of parasitemia undetectable even on several thick films [6].

The parasites load in infected donors may be very low; therefore, no clinical symptoms may be observed and Plasmodium species may live in the donors for years. This study was undertaken to determine the prevalence of malaria among voluntary and replacement blood donors.

\section{Material \& Methods}

Type of study: Retrospective study
Place of study: Blood Bank, Jhalawar hospital \& Medical college society, Jhalawar, Rajasthan covering the period between Jan 2017 to Dec 2017.

Sampling Methods: All records including TTI records, donor registers, completely filled donor forms, which included the type of donation (voluntary/replacement), the patient's details, pre-donation questionnaire, counselling details and medical examination findings available for each case were analysed. The samples from all blood donations were screened for HIV 1-2, HBsAg, HCV, syphilis and malaria. We at our blood bank, have been routinely screening all donated units of blood for malaria using RDT, based on immunochromatographic methods detecting antigens, histidinerich protein 2 (HRP2- $P$. falciparum), and p-lactate dehydrogenase ( $\mathrm{pLDH}-P$. vivax). Field stained thick and thin smears were madeof all positive cases to corroborate the results of RDT.

Statistical Methods: All Data were collected for malaria and analysed.

\section{Result}

Out of the 16495 blood donors, 5013(30.39\%) were voluntary donors and 11482 (69.61\%) were replacement donors. Maximum blood donors were Rh positive. There was a higher rate of male blood donation than females. Most of the donors were from age groups of 20-40 years. Thus indicating more youngster population as donors

Table-1: VariousTTI among total blood donors.

\begin{tabular}{|c|c|c|c|}
\hline $\begin{array}{c}\text { Transfusion transmitted } \\
\text { infections(TTI) }\end{array}$ & $\begin{array}{c}\text { Voluntary } \\
\text { donors(5013) }\end{array}$ & $\begin{array}{c}\text { Replacement } \\
\text { donors(11486) }\end{array}$ & Totaldonors(16495) \\
\hline Malaria & $\mathbf{0}$ & $\mathbf{5}$ & $\mathbf{5}$ \\
\hline HIV & 03 & 202 & 311 \\
\hline Hepatitis B & 109 & 31 & 34 \\
\hline Hepatitis C & 03 & 4 & 4 \\
\hline Syphilis & 0 & & \\
\hline
\end{tabular}

Table-2: Percentage of various infections in total TTI.

\begin{tabular}{|c|c|}
\hline Transfusion transmitted infections & \% of Total TTI \\
\hline Malaria & $\mathbf{1 . 3 4 \%}$ \\
\hline HIV & $4.58 \%$ \\
\hline Hepatitis B & $83.82 \%$ \\
\hline Hepatitis C & $9.16 \%$ \\
\hline Syphilis & $1.078 \%$ \\
\hline
\end{tabular}

Totally, 2.25\% $(n=371)$ bags were seropositive for transfusion transmitted infections (TTI) out of 16495 donors. Prevalence of Hepatitis B is highest $1.88 \%$ (311 donors) followed by infected with HCV 0.20\% (34 donors), HIV $0.10 \%$ (17 donors), malaria $0.03 \%$ (5 donors) and syhlilis $0.024 \%$ (4 donors) (Table 1). Hepatitis B was the leading cause among the TTI $83.82 \%$ followed HCV $9.16 \%$ and HIV $4.58 \%$ (Table 2).5 out of 16495 donor population were positive on Immuno chromatographic rapid diagnostic test for malarial antigen detection. In our study all 5 malaria positive donors were replacement donor. 
Original Research Article

\section{Discussion}

Malaria, one of the most important parasitic diseases inunder-developed countries, is a serious transfusion transmitted infection ranked after viral hepatitis and HIV.

The extensive use of blood and its products, and close contacts of human beings, enhanced the risk of transfusion transmitted malaria. Plasmodium species can be transmitted by transfusion of cellular components in labile blood products, and unlikely by frozen/thawed therapeutic plasma. All Plasmodium species are able to survive in stored blood, even if frozen, and retain their viability for at least 1 week, possibly well over 10 days depending on the conditions of storage; in fact, microscopically detectable malaria parasites were present even after 28 days of storage at $4{ }^{\circ} \mathrm{C}$ although a decrease of infectivity after 2 weeks was observed [6,7,8]. Asymptomatic carriers have potential role as the source of infection for Anopheles vectors as well as blood recipient.

Presence of Plasmodium falciparum inblood may lead to fatalities when the blood is transfused especially in the children under 5 years, pregnant women, and accident victims etc [6]. A recent international forum showed that in Europe, as well as the USA, prevention of transfusion associated protozoa infections depend mainly on selection of donors using questionnaires. A donor is rejected for 3 years after their last visit to the endemicarea [9]. Persons from the non endemic areas, who visited the malaria endemic area, are rejected for 4-12 months [10]. Over the last decade only a few cases of transfusion transmitted malaria were reported in various countries.

There is evidence that $\mathrm{ABO}$ histocompatibility of blood groupis not correlated to the incidence of malaria [9], but it has been linked as a coreceptor in parasite and vascular cytoadherence with higher rosette rates among non group $\mathrm{O}$ compared to group Oerythrocytes [11]. Donors who are implicated asthe source of transfusion transmitted malariacases typically have very low level of parasitemia undetectable even on several thick films [12]. Several studies have demonstrated an overall high sensitivity of Histidine Rich Protein (HRP 2) based diagnostic assays and their potential clinical utility for the diagnosis of malaria in symptomatic patients $[13,14,15]$.

In our study there are only 5 cases(all cases found in replacement donors) found positive on Rapid detection test by immunochromatography $(0.03 \%$ prevalence rate). which was comparable with study conducted by Bahadur et al (prevalence 0.03\%) [5], Fernandes $\mathrm{H}$ et al (prevalence 0.01\%)[16], Pallavi et al were unable to find a single case of malaria [17], Yadav et al were unable to find a single case of malaria [18], Negi et al (prevalence 0.002\%) [19], Rajesh Kumar et al (prevalence 0.006\%) [20], Fulzele et al (prevalence 0.0177\%)[21] and Akanksha Rawat et al (prevalence rate 0.06\%) [22]. Authors Ali MSM et al[23], Okocha EC et al[24], Owusu-Ofori Alex K et al[25] found very high prevalence of $6-55 \%$ in their studies may be due to high endemic area.

Table-3: Comparison-malaria prevalence of various studies with present study.

\begin{tabular}{|c|l|c|}
\hline S.N. & Study & Malaria positivity (\%) \\
\hline 1 & Bahadur et al, LadyHarding MC, Delhi [5] & $0.03 \%$ \\
\hline 2 & Fernandes H et al, Mangalore (India)[16] & $0.01 \%$ \\
\hline 3 & Pallavi et al, Mysore[17] & $0.00 \%$ \\
\hline 4 & Yadav et al, Central India [18] & $0.00 \%$ \\
\hline 5 & Negi et al, Uttarakhand [19] & $0.002 \%$ \\
\hline 6 & Rajesh kumar et al, Ludhiana [20] & $0.006 \%$ \\
\hline 7 & Fulzele et al, Mumbai [21] & $0.0177 \%$ \\
\hline 8 & Akanksha Rawat et al, Delhi [22] & $0.06 \%$ \\
\hline 9 & Ali MSM et al, Sudan [23] & $6.5 \%$ \\
\hline 10 & Okocha EC et al, Nigerian teaching hospital[24] & $30.2 \%$ \\
\hline 11 & Owusu-Ofori Alex K et al, Northern Nigeria[25] & $55 \%$ \\
\hline 12 & Present study & $0.03 \%$ \\
\hline
\end{tabular}

The drugs and cosmetic act in India mandates the testing for malaria but there is no definite guidelines onthe choice of the test. Since apparently healthy individuals those selected for blood donation may have very low density and may be easily missed [26]. Donors who are considered as the source of transfusion transmitted malaria cases, typically have very low level of parasitemia. Which undetectable even on thick smears. 
Original Research Article

Malaria antibody screeningis not indicative of active infection andresults in unnecessary high discarding of collected blood units. Malaria antibody may persist up to several years after infection. PCR test have limited availability. Also malaria immunoprophylaxis to all blood recipients is also not feasible practically. Post-transfusion malaria may cause severe clinical symptoms in the recipients, especially in those with no previous exposure to malaria or in immunocompromised patients due to other coexisting diseases [27]. An important difference between the natural infection and TTM is that the former undergoes an initial asymptomatic phase (pre-erythrocytic) which allows the activation of innate immunity cells against malaria parasites. Infected blood transfusions directly release malaria parasites in the recipient's blood stream triggering the development of high risk complications and potentially leading to a fatal outcome [28]. Delayed or missed diagnosis of $P$. falciparum in particular increases the risk of severe disease which may be fatal especially in non-immune individuals.

In case a patient is transfused with a malaria positive blood, the patient can be given a curative regimen of antimalarials, especially when the patient falls into the malaria vulnerable group (children, pregnant women, immigrants from outside malarious regions).

\section{Conclusion}

Our study result showed that Blood donors in Blood Bank, Jhalawar Hospital \& Medical College Society, Jhalawar, Rajasthan have low prevalence of malaria. Voluntary donations are safer as compared to replacement donation.

Recommendations: Use of rapid detection devices with peripheral smear screening of positive cases (2) strict donor selection, proper donor testing and post testing counseling. (3) Voluntarily blood donations should be encouraged so as to prevent blood donations from being made under emergency situations because in such cases the likelihood of transfusing infected blood will be higher.

\section{Contribution from authors}

- Dr. Manish Kumar: Preparation of manuscript, Data collection, Data compiling, literature review, final approval.

- Dr. Brajendra Shakyawal: Manuscript editing, literature review, final approval

- Dr. Yogendra Madan: Literature review, Final approval

Funding: This research did not receive any specific grant from any funding agency in the public, commercial or nonprofit organizations.

Ethical approval: The study was conducted after ethical approval by the Institutional Ethics Committee.

Findings: Nil; Conflict of Interest: None initiated Permission from IRB: Yes

\section{References}

1. Kulkarni N. Analysis of the seroprevalence of HIV, $\mathrm{HBsAg}, \mathrm{HCV}$ and syphilitic infections detected in the pretranfusion blood: A short report. International
Journal of Blood Transfusion and Immunohematology 2012; 2:1-3. doi: https://doi. org/10. 5348/ijbti-2012-6SR-1

2. Choudhury N, Desai P. Blood bank regulations in India. Clin Lab Med. 2012 Jun; 32(2):293-9. doi: 10. 1016/j. cll.2012.04.002.

3. Kitchen AD, Chiodini PL. Malaria and blood transfusion. Vox Sang. 2006 Feb;90(2):77-84. DOI:10. 1111/j. 1423-0410.2006.00733.x

4. Oh JS, Kim JS, Lee CH, et al. Evaluation of a malaria antibody enzyme immunoassay for use in blood screening. Mem Inst Oswaldo Cruz. 2008 Feb;103(1): 75-8. Epub 2008 Jan 31.

5. Bahadur S, Pujani M, Jain M. Use of rapid detection tests to prevent transfusion-transmitted malaria in India. AJTS [serial online] 2010 [cited 2011 Apr 3];4:pp 140141. doi: https://doi.org/10.4103/0973-6247.67033

6. Kark JA (1982). Malaria Transmitted by Blood Transfusion In: Infections Complications of Blood Transfusion (Tabor, E. ed.) Academic Press, New York. Pp: 92-126.

7. Bruce-Chwatt LJ. Transfusion malaria. Bull World Health Organ. 1974;50(3-4):337-46.

8. Chattopadhyay R, Majam VF, Kumar S. Survival of Plasmodium falciparum in human blood during refrigeration. Transfusion. 2001;51:630-635. doi: 10 . 1111/j. 1537-2995.2010.02872.x.

9. FDA (2006). Workshop on Testing for Malarial Infections in BloodDonors.FAD/CBER-FDAWork-shop. http//www.fda.gov/cber/blood/malaria July 12, 2006.

10. Hung CC, Chang SC, Chen YC, et al. Plasmodium vivax infection in a renal transplant recipient: report of a case. J Formos Med Assoc. 1994 Oct;93(10):888-9. 
11. Fischer PR, Boone P. Short report: severe malaria associated with blood group. Am J Trop Med Hyg. 1998 Jan;58(1):122-3.

12. Csert CM and DZIK WH(2007). The ABO bllod group system and plasmodium falciparum malaria. Blood 2007oct;110(7):2250-2258.doi: https://doi. org/ 10. 1182/blood-2007-03-077602

13. Reesink HW. European strategies against the parasite transfusion risk. Transfus Clin Biol. 2005 Feb; 12 (1):1-4. DOI:10.1016/j.tracli.2004.12.001

14. Beadle C, Long GW, Weiss WR, et al. Diagnosis of malaria by detection of Plasmodium falciparum HRP-2 antigen with a rapid dipstick antigen-capture assay. Lancet. 1994 Mar 5;343(8897):564-8.

15. Humar A, Ohrt C, Harrington MA, et al. Parasight F test compared with the polymerase chain reaction and microscopy for the diagnosis of Plasmodium falciparum malaria in travelers. Am J Trop Med Hyg. 1997 Jan; 56 (1): 44-8.

16. Fernandes H, D'souza PF, D'souza PM. Prevalence of transfusion transmitted infections in voluntary and replacement donors. Indian J Hematol Blood Transfus. 2010 Sep;26(3):89-91. doi: 10.1007/s12288-010-00440. Epub 2010 Oct 21.

17. Pallavi P, Ganesh CK, Jayashree K, et al. Seroprevalence and trends in transfusion transmitted infections among blood donors in a university hospital blood bank: a 5 year study. Indian J Hematol Blood Transfus. 2011 Mar;27(1):1-6. doi: 10.1007/s12288-010-0047-x. Epub 2010 Dec 14.

18. Yadav BS, Varma AV, Singh P, Kumar R, Bandi PK.Seroprevalence of transfusion-transmitted infections (TTIs) in blood donors: a study from central India. Int J Med Sci Public Health 2016;5:1158-1162doi:http://dx. doi.org/10.5455/ijmsph.2016.26102015182

19. Negi $G^{1}$, Gaur DS. Trends of transfusion transmissible diseases among blood donors at uttarakhand, India. Indian J Community Med. 2014 Jul; 39 (3): 183-6. doi: 10.4103/0970-0218.137161.
20. Rajesh K,SGupta,A Kaur, A Jindal, H Sharma. Sero-prevalence and Changing Trends of Transfusion Transmitted Infections among Blood Donors in a Tertiary Care Hospital. Indian J Comm Health.2015; 27 (1): $25-29$

21. Fulzele Parag Prabhakar, Yasmeen KhatibInfectious Disease Screening and Trendsin Blood Donors in a Hospital based Blood Bank in Mumbai, Western India - International Journal of Contemporary Medical Research Volume 4 | Issue 2 | February 2017

22. Akanksha Rawat, Preeti Diwakar - Seroprevalence $\&$ changing trends of transfusion-transmitted infections amongst blood donors in a Regional Blood Transfusion Centre in north India- Indian J Med Res 146, November 2017, pp 642- 645doi: 10.4103/ ijmr. IJMR_ 468_15

23. Ali MSM, Kadaru AAGMY, Mustafa MS. Screening blood donors for Malaria parasite in Sudan. Ethiop J Health Dev 2004;18(2):pp70-4. doi:http://dx. doi.org/10.4314/ejhd.v18i2.9940

24. Okocha EC, Ibeh CC, Ele PU, Ibeh NC. The prevalence of malaria parasitaemia in blood donors in a Nigerian teaching hospital. J Vector Borne Dis. 2005 Mar; 42(1):21-4.

25. Owusu-Ofori AK, Betson M, Parry CM, et al. Transfusion-transmitted malaria in Ghana. Clin Infect Dis. 2013 Jun;56(12):1735-41. doi: 10.1093/cid/cit130. Epub 2013 Mar 5.

26. Kaur P, Basu S. Transfusion-transmitted infections: existing and emerging pathogens. J Postgrad Med. 2005 Apr-Jun;51(2):146-51.

27. Uneke CJ, Ogbu O, Nwojiji V. Potential risk of induced malaria by blood transfusion in South-eastern Nigeria. Mcgill J Med. 2006 Jan;9(1):8-13.

28. Garraud O. Mechanisms of transfusion-linked parasite infection. Transfus Clin Biol. 2006 Nov;13(5): 290-7. Epub 2006 Dec 22. DOI:10.1016/j.tracli. 2006. 11.005

\section{How to cite this article?}

Manish Kumar, Shakyawal B, Madan Y. Prevalence of malaria among blood donors in blood bank, Jhalawar Hospital \& Medical College Society, Jhalawar, Rajasthan. Trop J Path Micro 2019;5(2):83-87.doi:10.17511/jopm.2019.i02.06. 